\title{
ANALISIS SENTIMEN REVIEW MEDIA MASSA MENGGUNAKAN METODE C4.5 BERBASIS FORWARD SELECTION
}

\author{
Arif Rakhman $^{1}$, M. Rifqi Tsani ${ }^{2}$ \\ Email : cakrakirana7@gmail.com,mokh.rifqi.tsani@gmail.com \\ D3 Teknik Komputer Politeknik Harapan Bersama \\ Jln. Mataram No. 09 Tegal Telp/Fax(0283) 352000
}

\begin{abstract}
Abstrak
Pertumbuhan jaringan sosial yang ada saat ini, membuat konsumenmenggunakan konten dalam media untuk membuat keputusan yang lebihbaik, analisis sentimen review diakui sebagai sumber informasi yangbermanfaat untuk pemantauan dan meningkatkan tingkat kepuasan konsumen. Beberapa konsumen menuangkan opini atau pengalaman merekamelalui media sosial seperti Facebook, Twitter, atau situs media yanglainnya. Saat ini, pendapat khalayak umum telah menjadi salah satu sumberyang begitu penting dalam berbagai review produk di jejaring sosial.Popularitas internet mendorong orang untuk mencari pendapat pengguna dari internet sebelum membeli produk tertentu. Klasifikasi sentimen bertujuan untuk mengatasi masalah ini dengan secara otomatis mengelompokkan review pengguna menjadi opini positif atau negatif.Dari Hasil penelitian analisis sentimen review media massa diperoleh metode forward selection untuk seleksi fitur dan algoritma C4.5 menghasilkan akurasi yang lebih baik, dibandingkan pada penelitian sebelumnya dimana hasil akurasi tertinggi sebesar $80.00 \%$. Pada analisis sentimen review media massa menggunakan C4.5 dengan seleksi fitur forward selection mendapatkan hasil akurasi sebesar 84,00\%. Dengan demikian dapat disimpulkan bahwa penelitian klasifikasi dengan algoritma C4.5 pada analisis sentimen review media massa dapat ditingkatkan akurasinya dengan menggunakan forward selection sebesar $4.00 \%$.
\end{abstract}

Kata Kunci:Sentimen Review, Decision tree, Forward selection

\section{Pendahuluan}

Analisis Sentimen (Sentiment Analysis) merupakan teknik untuk mengenali opini positif maupun negatif ${ }^{[1]}$. Media massa adalah sarana penyampaian pesan yang berhubungan langsung dengan masyarakat luas misalnya radio, televisi, dan surat kabar. Media massa merupakan suatu penemuan teknologi yang luar biasa, yang memungkinkan orang untuk mengadakan komunikasi bukan saja dengan komunikasi yang mungkin tidak pernah akan dilihat akan tetapi juga dengan generasi yang akan datang. Dengan demikian maka media massa dapat mengatasi hambatan berupa pembatasan yang diadakan oleh waktu, tempat dan kondisi geografis. Penggunaan media massa karenanya memungkinkan komunikasi dengan jumlah orang yang lebih banyak. Menurut [2] media massa sebagai alat penyampaian pada masyarakat tentang programprogram pembangunan nasional. Media massa berperan penting dalam kehidupan sehari-hari seperti untuk memberitakan fakta kehidupan ekonomi, pembangunan, politik dan informasi lainya. Saat ini banyak bermunculan media massa baik itu elektronik maupun cetak. Sebagai konsumen media massa perlu memilih media massa yang berkualitas baik, sehingga informasi yang didapatkan juga berkualitas dan akurat.Pertumbuhan jaringan sosial yang ada saat ini, membuat konsumen menggunakan konten dalam media untuk membuat keputusan yang lebih baik, analisis sentimen review diakui sebagai sumber informasi yang bermanfaat untuk pemantauan dan meningkatkan tingkat kepuasan konsumen ${ }^{[3]}$. Beberapa konsumen menuangkan opini atau pengalaman mereka melalui media sosial seperti Facebook, Twitter, atau situs media yang lainnya. Saat ini, pendapat khalayak umum telah menjadi salah satu sumber yang begitu penting dalam berbagai review produk di jejaring sosial ${ }^{[4]}$. Popularitas internet mendorong orang untuk mencari pendapat pengguna dari internet sebelum membeli produk tertentu. Pendapat orang-orang dapat mengurangi ketidakpastian terhadap suatu produk tertentu dan membantu konsumen menyimpulkan kualitas suatu produk tertentu ${ }^{[5]}$. Banyak situs yang menyediakan berbagai macam review tentang suatu produk yang dapat mencerminkan pendapat pengguna ${ }^{[4]}$. Salah satu contohnya adalah situs internet Yelp. Yelp adalah situs yang berisi berbagai macam review, seperti media massa, restoran, hotel, makanan, elektronik dan lain sebagainya. Jika membaca review tersebut secara keseluruhan bisa memakan waktu dan sebaliknya jika hanya sedikit review yang dibaca, hasil evaluasi akan bias. Klasifikasi sentimen bertujuan untuk mengatasi masalah ini dengan secara otomatis 
mengelompokkan review pengguna menjadi opini positif atau negatif.

\section{Metode Penelitian}

\subsection{Kerangka Penelitian}

Penelitian ini adalah penelitian eksperimen analisis sentimen review dengan dataset review media massa. Penelitian ini bertujuan untuk menguji model klasifikasi yang terbaik untuk klasifikasi analisis sentimen review. Pada gambar 1 menggambarkan model desain penelitian dari tahap pengumpulan data, pengolahan awal, metode yang diusulkan, eksperimen dan pengujian sampai hasil evaluasi dan validasi.

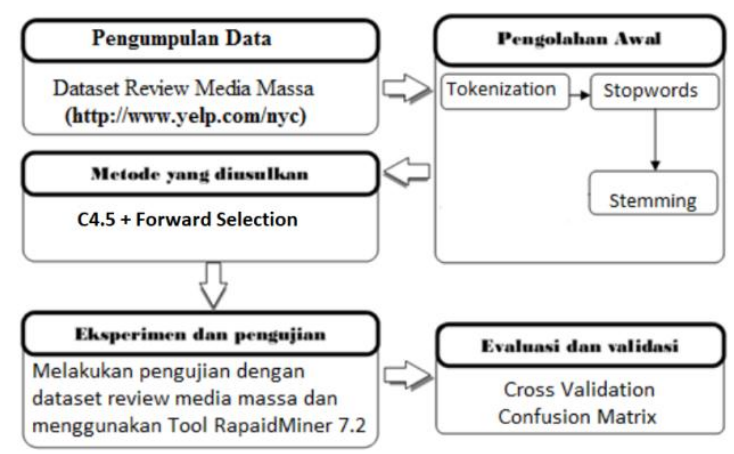

Gambar 1 Kerangka Penelitian

\subsection{Bahan Penelitian}

Dataset review media massa diambil dari tahun 2010 sampai 2018 di situs review Yelp.

\subsection{Alat Penelitian}

Alat penelitian meliputi:

1. Hardware

Beberapa perangkat keras dibutuhkan dalam aktifitas merancang dan implementasi program. Perangkat keras utama yang dibutuhkan antara lain komputer dengan minimal spesifikasi prosesor intel core I3 dan memory $4 \mathrm{~Gb}$. Printer multifungsi minimal setara Canon MP 140 dilengkapi scanner.

2. Software

Selain dukungan perangkat keras, dibutuhkan pula perangkat lunak yang digunakan dalam merancang dan mengimplementasi program. Perangkat lunak yang digunakan Rapidminer versi 6.5.

Untuk mendapatkan data yang benar-benar akurat, relevan, valid dan reliable maka pengumpulan data dilakukan dengan cara:

1. Sumber Data Primer

Adalah data yang diperoleh secara langsung dari objek penelitian, baik melalui pengamatan maupun pencatatan terhadap obyek penelitian.

a. Observasi

Pengumpulan data melalui pengamatan dan pencatatan terhadap gejala atau peristiwa yang diselidiki pada obyek penelitian secara langsung, misalnya mengamati aktifitas cara pengajaran masing-masing dosen dan jurnal pembelajaran.

b. Wawancara

Pengumpulan data melalui tatap muka dan tanya jawab langsung dengan sumber data atau pihak-pihak yang berkepentingan yang berhubungan dengan penelitian.

2. Sumber Data Sekunder

Adalah data yang diambil dari bukubuku, dokumentasi, dan literatur-literatur, Meliputi:

a. Studi Kepustakaan

Pengumpulan data dari buku-buku yang sesuai dengan tema permasalahan, misalnya buku tentang Sistem pendukung keputusan.

b. Studi Dokumentasi

Pengumpulan data dari literaturliteratur dan dokumentasi dari Internet, diktat, dan sumber informasi lain.

\section{Hasil dan Pembahasan}

\subsection{Pra processing data}

Dataset review media massa diambil dari tahun 2010 sampai 2018 di situs review Yelp. Data tersebut masih berupa sekumpulan teks yang terpisah dalam bentuk dokumen. Data review positif disatukan dalam satu folder dan diberi nama positif, sedangkan data review negatif disatukan dalam satu folder dan diberi nama negatif.

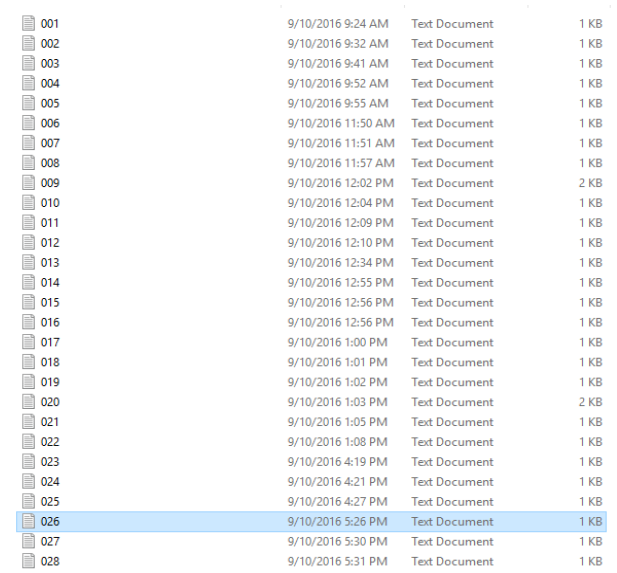

Gambar 2. Contoh dataset 


\subsection{Pembahasan}

\subsubsection{Ekperimen Dengan RapidMiner 6.5}

RapidMiner Sebagai software pengolah data mining meneyediakan tool untuk membuat decision tree. Hal ini tentu akan memudahkan kita membuat decision tree dengan menggunakan RapidMiner dibandingkan membuat decissio tree secara manual. Prosesnya seperti gambar dibawah ini:

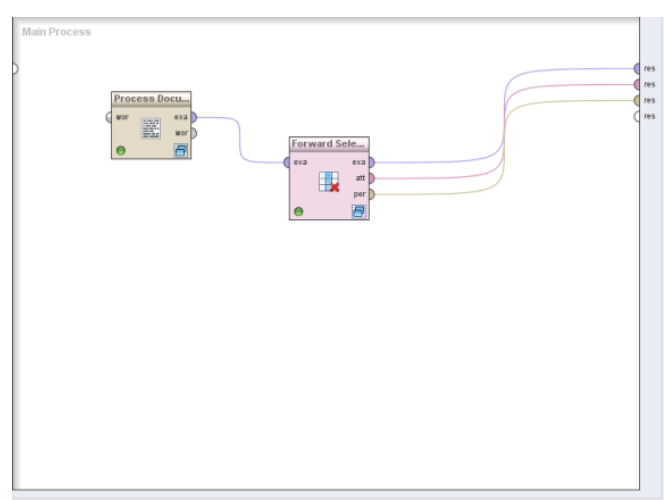

Gambar 3. Main proses

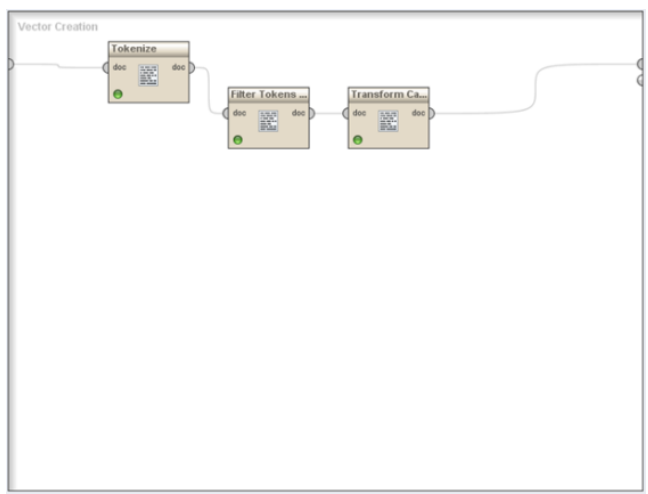

Gambar 4. Pre prosesing

\subsubsection{Validasi pada Forward Selection}

Tahapan forward selection:

a. Mulai dengan tidak ada prediktor variabel (model hanya berisi konstanta

b. Untuk semua prediktor variabel tidak dalam model, pilih satu variabel dengan nilai p-value terkecil dan kurang dari taraf nyata $\alpha$

c. Ulangi langkah b, hingga tidak terdapat predictor variabel yang dapat ditambahkan ke dalam model.
Langkah rapidminer validasi sebagai berikut :

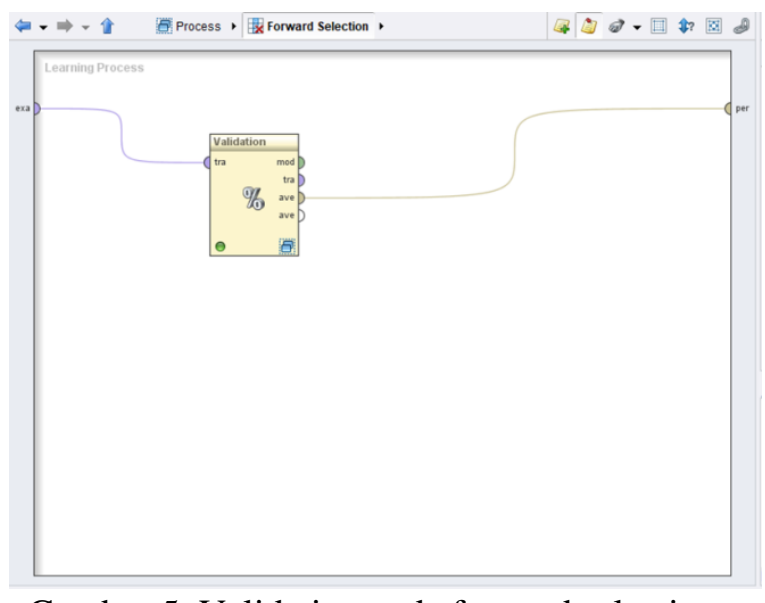

Gambar 5. Validation pada forward selection

\subsubsection{Validasi dengan metode $\mathrm{C}$ 4.5}

Algoritma C4.5 juga menggunakan kriteria gain dalam menentukanfitur yang menjadi pemecah node pada pohon yang diinduksi.besar. Seperti pada gambar berikut :

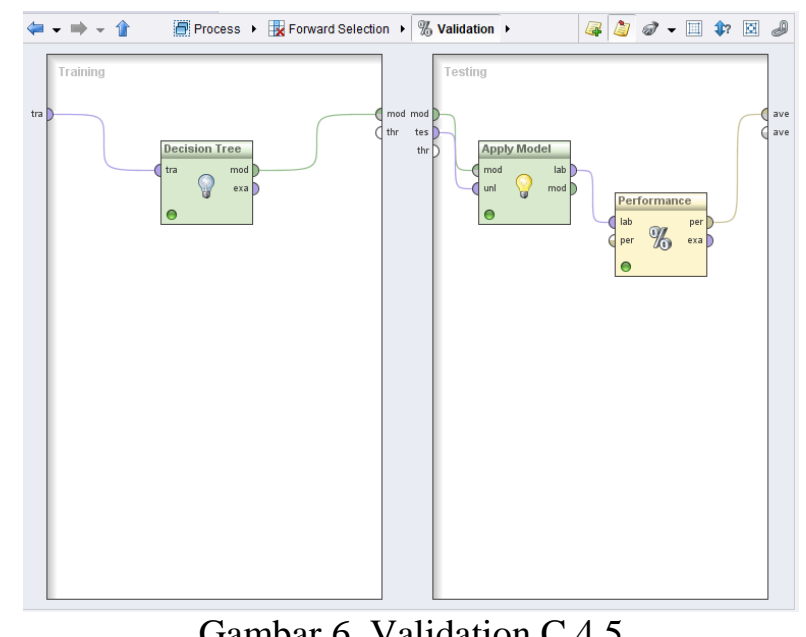

Gambar 6. Validation C 4.5

\subsubsection{Evaluasi dan Validasi Penelitian}

Pada penelitian klasifikasi untuk evaluasi hasil pengujian dilakukan dengan menghitung nilai dari accuracy, precision dan recall. Eksperimen ini menggunakan data sebanyak 200 dokumen review media massa. Pada tabel 1 menggambarkan confunsion matrik dari eksperimen yang dilakukan menggunakan pengujian 7 folds menggunakan algoritma C4.5 dan Forward Selection. 
Tabel 1. Confunsion Matrik Algoritma C4.5 dan Forward Selection

\begin{tabular}{|c|c|c|c|}
\hline \multicolumn{4}{|c|}{ Accuracy: $84.00 \%+/-5.83 \%$ (mikro: $84.00 \%)$} \\
\hline & $\begin{array}{c}\text { True } \\
\text { Negatif }\end{array}$ & $\begin{array}{c}\text { True } \\
\text { Positif }\end{array}$ & $\begin{array}{c}\text { Class } \\
\text { Precision }\end{array}$ \\
\hline $\begin{array}{c}\text { Prediksi } \\
\text { Negatif }\end{array}$ & $72(\mathrm{TN})$ & $4(\mathrm{FP})$ & $94.74 \%$ \\
\hline $\begin{array}{c}\text { Prediksi } \\
\text { Positif }\end{array}$ & $28(\mathrm{FN})$ & $96(\mathrm{TP})$ & $77.42 \%$ \\
\hline Class Recall & $72.00 \%$ & $96.00 \%$ & \\
\hline
\end{tabular}

\section{a. Nilai Accuracy}

$$
\text { Accuracy }=\frac{T P+T N}{T P+T N+F P+F N}
$$

$$
\begin{aligned}
\text { Accuracy } & =\frac{96+72}{\text { Accuracy }}=\frac{96+72 \cdot 10-3}{200}
\end{aligned}
$$

Accuracy $=0.84=84.00 \%$

b. Nilai Recall

$$
\begin{aligned}
& \text { Recall }=\frac{T P}{T P+F P} \\
& \text { Recall }=\frac{96}{96+4} \\
& \text { Recall }=-96-100
\end{aligned}
$$

[5] N. Sian, N. Hu, and E. K. Clemons, "Electronic Commerce Research andApplications Do online reviews reflect a product ' $\mathrm{s}$ true perceived quality? Aninvestigation of online movie reviews across cultures," Electron. Commer. Res.Appl., vol. 9, no. 5, pp. 374-385, 2010.

[6] Monarizqa, Nurvirta, and Ir Lukito Edi Nugroho. Penerapan AnalisisSentimenPada Twitter Berbahasa Indonesia Sebagai Pemberi Rating. Diss. Universitas Gadjah Mada, 2014.

[7] Naufal, Abdul Razak, Romi Satria Wahono, and Abdul Syukur. "PenerapanBootstrapping untuk Ketidakseimbangan Kelas dan Weighted Information Gainuntuk Feature Selection pada Algoritma Support Vector Machine untukPrediksi Loyalitas Pelanggan." Journal of Intelligent Systems 1.2 (2015): 98-108.

[8] Tan, Songbo, and Jin Zhang. "An empirical study of sentiment analysis forchinese documents." Expert Systems with applications 34.4 (2008): 2622-2629. 
[9] Saraswati, Ni Wayan Sumartini. "Naïve Bayes Classifier Dan Support VectorMachines Untuk Sentiment Analysis." SESINDO 2013 (2013).

[10] Ling, Juen, I. Putu Eka N Kencana, and Tjokorda Bagus Oka. "Analisis Sentimen Menggunakan Metode Naïve Bayes Classifier Dengan Seleksi Fitur Chi Square." E-Jurnal Matematika 3.3 (2014): 92-99.

[11] W. Medhat, A. Hassan, and H. Korashy, "Sentiment analysis algorithms and applications : A survey," AIN SHAMS Eng. J., 2014.

[12] B. Pang and L. Lee, "Opinion Mining and Sentiment Analysis," Foundations and Trends in Information. Retrieval. vol. 2, pp. 1-135, 2008.

[13] Strapparava, Carlo, and Rada Mihalcea. "Semeval-2007 task 14: Affective text." Proceedings of the 4th International
Workshop on Semantic Evaluations. Association for Computational Linguistics, 2007..

[14] Su, Fangzhong, and Katja Markert. "From words to senses: a case study of subjectivity recognition." Proceedings of the 22nd International Conference on Computational Linguistics-Volume 1. Association for Computational Linguistics, 2008.

[15] Christopher D.Manning, "A. Introduction and I. Retrieval, Online edition (c) 2009 Cambridge UP," no. c, 2009.

[16] Eko Prasetyo, Data Mining Mengolah Data Menjadi Informasi menggunakan Matlab. Yogyakarta: ANDI, 2014.

[17] I. M. M. Ghani, S. Ahmad, and K. Terengganu, "Comparison Methods of Multiple Linear Regressions in Fish Landing," Aust. J. Basic Appl. Sci., vol. 5, no. 1, pp. 25-30, 2011. 